\title{
DINÂMICA DO USO E COBERTURA DA TERRA DO MUNICÍPIO DE FLORESTA, PE
}

\author{
Emanuel Araújo Silva ${ }^{1}$, Rinaldo Luiz Caraciolo Ferreira² ${ }^{2}$ José Antônio Aleixo da Silva ${ }^{3}$, Iêdo Bezerra \\ $\mathrm{Sá}^{4}$, Simone Mirtes Araújo Duarte ${ }^{5}$
}
${ }^{1}$ Eng. Florestal, Doutorando em Engenharia Florestal, UFSM, Santa Maria, RS, Brasil - mad_emanuel@ hotmail.com ${ }^{2}$ Eng. Florestal, Dr., Depto. de Ciência Florestal, UFRPE, Recife, PE, Brasil - rinaldo@dcfl.ufrpe.br
${ }^{3}$ Eng. Agrônomo, Ph.D., Depto. de Ciência Florestal, UFRPE, Recife, PE, Brasil - aleixo@dcfl.ufrpe.br
${ }^{4}$ Eng. Florestal, Dr. em Geoprocessamento, EMBRAPA, Petrolina, PE, Brasil - iedo@cpatsa.embrapa.br
${ }^{5}$ Eng $^{\mathrm{a}}$. Agrícola, Dra ${ }^{\text {a }}$ Depto. de Ciência Florestal, UFRPE, Recife, PE, Brasil - mirtes.duarte@dcfl.ufrpe.br

Recebido para publicação: 02/07/2012 - Aceito para publicação: 26/08/13

\begin{abstract}
Objetivou-se mapear a dinâmica de mudança do uso da terra e da cobertura florestal no período de 21 anos (1987 a 2008), no município de Floresta, PE. Foram utilizadas imagens de satélite LANDSAT 5 nos períodos de 1987, 1997 e 2008. Utilizou-se o aplicativo SPRING para elaboração da base de dados cartográficos e do processamento digital das imagens. As imagens foram segmentadas e classificadas pelo algoritmo de Bhattacharya, com a finalidade de produzir mapas temáticos nos seguintes usos da terra: vegetação densa, vegetação semidensa, solo exposto, agropecuária (cultivos/pecuária), corpos d'água e mata ciliar. Para um período de 21 anos, a cobertura florestal recuou $14,83 \%$. O solo exposto teve um ganho de $8,61 \%$, a classe agropecuária acumulou um ganho de $5,75 \%$, os corpos d'água, ao longo do tempo, demonstraram um aumento de 4,03\% e a mata ciliar teve tendência à queda ao longo dos períodos analisados, com uma perda total de $3,57 \%$. Esses dados refletem as transformações por que o município de Floresta vem passando quanto ao uso da terra. A diminuição da cobertura florestal do município entre 1987 e 2008 foi a principal consequência da interação clima e pressão antrópica por recursos florestais, necessidade de expansão urbana e atividades agropecuárias.

Palavras chave: Sensoriamento remoto; gestão florestal; semiárido; caatinga.
\end{abstract}

Resumo

\begin{abstract}
Use dinamics and land cover in Floresta-PE. The objective was to map the dynamic changes of land use and forest cover in the last 21 years (1987 to 2008), the City of Forest-PE. We used satellite images LANDSAT 5 periods in 1987, 1997 and 2008. We used the SPRING software for compiling the database and cartographic processing of digital images. The images were segmented and classified by the algorithm Bhattacharya, in order to produce thematic maps in the following land uses: dense vegetation, semi-dense vegetation, bare soil, agriculture (crops / livestock), water bodies and riparian vegetation. For a period of 21 years the forest cover decreased by $14.83 \%$. The soil was exposed to a gain of $8.61 \%$, the class agricultural accumulated gain of $5.75 \%$, water bodies, over time, showed an increase of $4.03 \%$ and riparian tended to fall over the periods analyzed with a total loss of $3.57 \%$. These data reflect the changes that the city has been experiencing as of forest land use. The decrease in forest cover between 1987 and 2008 the city was the main consequence of the interaction of climate and anthropogenic pressure forest resources, need for urban expansion and agricultural activities.

Keywords: Remote sensing; forest management; semiarid; caatinga.
\end{abstract}

\section{INTRODUÇÃO}

O semiárido brasileiro tem sido definido como tendo $855.000 \mathrm{~km}^{2}$, segundo o Banco do Nordeste do Brasil (BNB, 2005), e abrange boa parte do Nordeste. Nessa área, a degradação dos recursos naturais tem ocasionado a diminuição da fertilidade do solo, acarretando a perda de áreas naturais e, consequentemente, podendo reduzir a composição e diversidade das comunidades (METZGER, 1999) e formar paisagens estruturalmente pobres (TILMAN et al., 2001). Um exemplo preocupante disso é a 
degradação do bioma Caatinga, exclusivamente brasileiro, onde a vegetação é considerada como a mais rica floresta seca da América do Sul (LEAL et al., 2005).

A vegetação natural da Caatinga vem sofrendo grande pressão antrópica, sendo explorada de forma desordenada e se fazendo presente em boa parte dos recursos florestais na região, caracterizando-se pela ausência de critérios técnicos no corte da vegetação e, consequentemente, ameaçando de extinção várias espécies vegetais e animais (RIBEIRO et al., 2001). Portanto, medidas que visem prevenir impactos negativos ou reduzir sua magnitude devem ser tomadas para evitar esse cenário.

As informações que podem ser produzidas com os dados dos sensores do satélite possuem uma grande importância para o estudo do uso da terra e da cobertura vegetal no bioma Caatinga, pois poderá proporcionar um suporte para tomada de decisões, como, por exemplo, medidas de prevenção e recuperação de regiões atingidas por processos de desertificação em consequência de ação antrópica ou natural.

Inserido no bioma Caatinga, o município de Floresta $(\mathrm{PE})$ vem apresentando problemas referentes ao controle do desmatamento, pois, nas últimas décadas, a pressão que a agricultura e pecuária vem exercendo na região aumentou de forma desordenada, contribuindo para a degradação da vegetação local.

Dessa forma, há a necessidade de se criar um banco de dados do município e avaliar, através da classificação de imagens, a situação em que se encontra o desmatamento da vegetação local. Sendo assim, torna-se importante a realização de estudos de sensoriamento remoto voltados para o problema da degradação ambiental, de forma a aumentar a capacidade do homem de responder de maneira eficaz e rápida aos processos tanto erosivos quanto de aumento do uso e ocupação do solo que assolam o bioma Caatinga.

Portanto, neste estudo objetivou-se mapear e criar um banco de dados sobre a dinâmica de mudança do uso da terra e da cobertura vegetal nos últimos 21 anos (1987 a 2008), no município de Floresta, sertão de Pernambuco, visando subsidiar a gestão florestal, bem como avaliar suas causas e efeitos.

\section{Vegetação}

Em se tratando da vegetação do município, há duas formações vegetacionais: a Caatinga, hiperxerófila pouco densa e arbustiva, e a floresta caducifólia, caracterizada pela elevação do terreno e denominada de brejo de altitude.

Para Mariano Neto (2001), as características da caatinga hiperxerófila são determinadas por fatores vitais, como baixo índice pluviométrico e temperaturas elevadas durante a estação seca, o que provoca aridez e incapacitação do solo predominantemente raso e pedregoso ou com afloramentos cristalinos, que inviabiliza a absorção da água. Nesse ambiente podem ser encontradas, entre outras espécies vegetais, o facheiro (Pilosocereus piauhiensis), a macambira (Bromelia laciniosa), o marmeleiro (Croton spp.) e juremas (Mimosa spp.). Na região de estudo, a hiperxerofilia é do tipo Caatinga arbustivoarbórea, caracterizada por vegetação densa em determinadas localidades, porém com estruturas irregulares, muitas vezes formando agrupamentos com descobrimento parcial do solo.

Em compensação, existe uma área onde a fitofisionomia é totalmente diferente da Caatinga que a cerca, os chamados de brejos de altitude. A vegetação natural dessas localidades é a floresta perenifólia ou subperenifólia, que recobre os topos e as vertentes de serras que, por sua vez, são circundadas por vegetação xerófila de caatinga, nas altitudes inferiores (ANDRADE-LIMA, 1960; ANDRADE; LINS, 1964; LINS, 1989).

A florística dos brejos é bastante heterogênea, formada por famílias importantes da Floresta Atlântica, elementos de ampla distribuição nas Américas e algumas espécies da Caatinga, nas áreas de transição com a Caatinga, bem como nas bordas e clareiras da mata (SALES et al., 1998). A vegetação caracteriza-se por apresentar um dossel florestal mais ou menos contínuo a 15 ou $20 \mathrm{~m}$ de altura e árvores emergentes esparsas, de 20 a $30 \mathrm{~m}$. Essas árvores frequentemente têm o tronco e ramos cobertos por briófitas e liquens, que formam comunidades surpreendentes pela diversidade de espécies (BALDINI, 2008).

\section{MATERIAIS E MÉTODOS}

\section{Área do estudo}

O município de Floresta está localizado a $433 \mathrm{~km}$ a oeste da cidade de Recife, na mesorregião São Francisco Pernambucano e microrregião Sertão de Itaparica. A área municipal ocupa $3674,9 \mathrm{~km}^{2}$. A 
sede municipal apresenta altitude de $316 \mathrm{~m}$ e coordenadas geográficas $8^{\circ} 36^{\prime} 02^{\prime}$ ' S de latitude e $38^{\circ} 34^{\prime} 05^{\prime}$ " W de longitude (CPRM, 2005) (Figura 1).

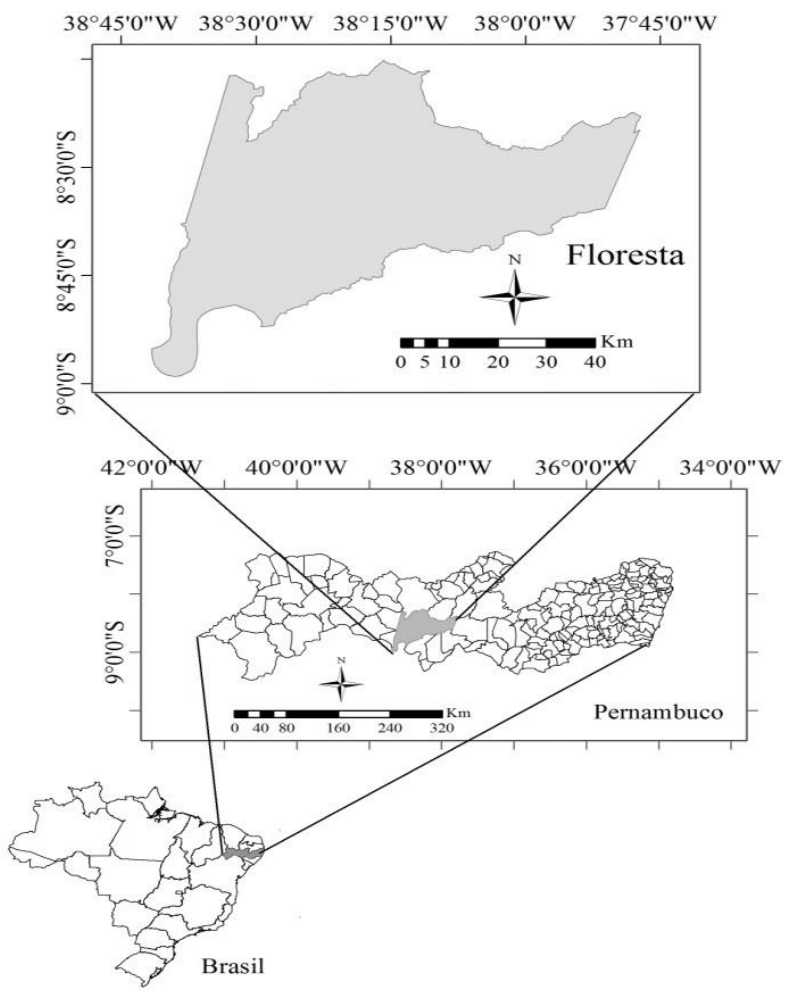

Figura 1. Esquema de localização do município de Floresta (PE).

Figure 1. Diagram showing the location of the Municipality of Floresta (PE).

De acordo com a classificação de Köppen, Floresta apresenta o clima do tipo BSw'h' (muito quente, semiárido, tipo estepe) e 4aTh da classificação de Gaussen, tropical quente de seca acentuada (JACOMINE et al., 1973). A temperatura média anual é de $26,5^{\circ} \mathrm{C}$ e as precipitações variam em torno de $623 \mathrm{~mm}$, concentrando-se nos meses de janeiro a maio, sendo março e abril os mais chuvosos. A evapotranspiração potencial média é de $1646 \mathrm{~mm}$ ao ano, com déficit hídrico anual de $1023 \mathrm{~mm}$ (EMPRESA BRASILEIRA DE PESQUISA AGROPECUÁRIA (EMBRAPA), 2001).

A vegetação é basicamente composta por Caatinga hiperxerófila com trechos de Floresta Caducifólia (CPRM, 2005). Dentre os cursos d'água que drenam a área em estudo, destaca-se o rio Pajeú (cujo principal afluente é o riacho do Navio, que é intermitente) que deságua no rio São Francisco.

\section{Obtenção de dados em campo}

Foram feitas incursões em campo, para marcação de pontos de GPS com as mesmas coordenadas geográficas, com o intuito de identificar o uso e a ocupação do solo, observações in loco e fotografias para fazer registros da paisagem, visando averiguar a veracidade do que foi obtido nas imagens. Isso permitiu conhecer a realidade dos fatores sociais, econômicos e ambientais, de forma mais precisa, havendo uma correlação entre os pontos levantados e o que foi pesquisado.

Foram utilizados materiais cartográficos e materiais de processamento e análise. Como materiais cartográficos, foram utilizadas imagens TM do satélite LANDSAT 5 órbita-ponto: 216-066 de 07 de outubro de 1987, 16 de setembro de 1997 e 01 de novembro de 2008; e carta de diagnóstico ambiental de Floresta (PE) elaborada pela EMBRAPA, na escala 1:100000, com impressão em 2000.

Como materiais de processamento e análise, foram utilizados computador, impressora e o Sistema de Processamento de Informações Georreferenciadas (SPRING), versão 5.1.3, desenvolvido e disponibilizado gratuitamente pelo Instituto Nacional de Pesquisas Espaciais (INPE). 
Para facilitar o trabalho em campo e interpretação de imagens digitais, seguiram-se os procedimentos do Manual Técnico de Uso da Terra desenvolvido pelo Instituto Brasileiro de Geografia e Estatística (IBGE, 2006). Foram também obtidos dados pluviométricos referentes ao período de estudo, por meio do Instituto de Tecnologia de Pernambuco (ITEP/LAMEPE), de Floresta, PE (Figura 2).

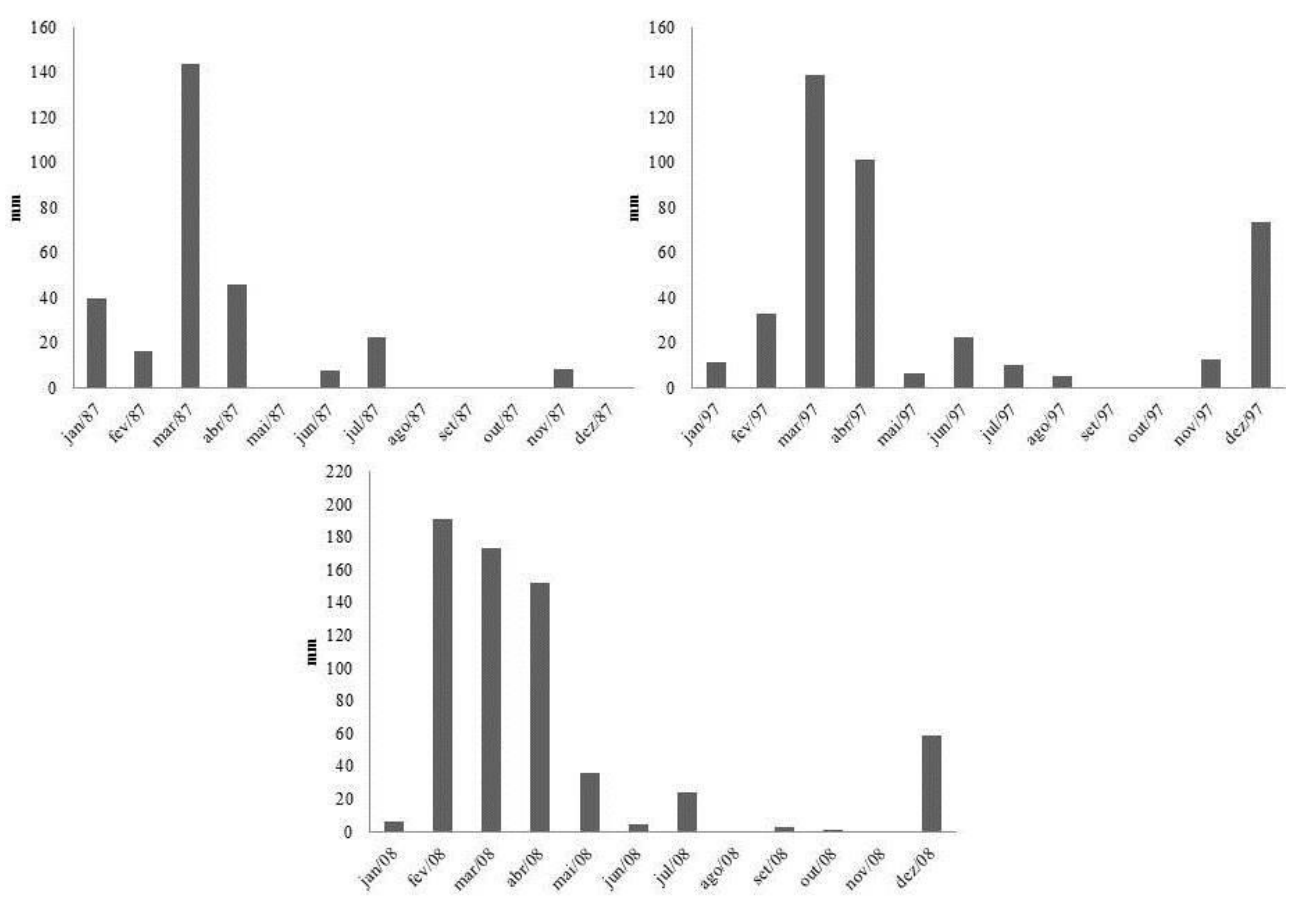

Figura 2. Dados mensais pluviométricos em 1987, 1997 e 2008 no município de Floresta (PE). Figure 2. Monthly rainfall data in 1987, 1997 and 2008 of the Municipality of Floresta (PE).

\section{Análise dos dados}

Inicialmente, as imagens obtidas foram importadas pelo Impima 5.1.3 no formato TIFF. Cada banda $(1,2,3,4,5$ e 7$)$ foi salva separadamente, excetuando-se a banda 6 , pois se trata da banda termal, em formato GRIB, para poder então ser trabalhada no SPRING 5.1.3.

Criou-se um projeto com o objetivo de definir a projeção cartográfica utilizada, sendo definido no presente trabalho a projeção LATLONG, datum de referência SAD69 e o retângulo envolvente que inclui as coordenadas da região: Long 1: oeste $38^{\circ} 48^{\prime}{ }^{\prime \prime}$, Long 2: oeste $37^{\circ} 42^{\prime} 3$ ", Lat 1: sul $9^{\circ} 2^{\prime} 1^{\prime \prime}$ e Lat 2: sul $8^{\circ} 6^{\prime} 18^{\prime \prime}$. Os primeiros dados inseridos no banco de dados foram os limites do município em formato shapefile e as imagens em formato GRIB. A seguir, as imagens foram georreferenciadas através de 20 pontos de controle, com erros médios inferiores a 0,7 , e posteriormente recortadas na região de interesse do município.

As imagens foram trabalhadas conforme a seguinte ordem:

1. Realce de contraste de imagem: a técnica de realce de contraste linear foi utilizada para melhorar a qualidade das imagens sob os critérios subjetivos do olho humano. Foi utilizada como um préprocessamento para sistemas de reconhecimento de padrões.

2. Operações aritméticas entre imagens: utilizaram-se três bandas (3, 4 e 5), nas cores vermelha, verde e azul, respectivamente, de uma mesma área geográfica. Realizou-se a operação tendo como resultado uma banda sintética representando a combinação das bandas originais, permitindo a compressão de dados.

3. Razão entre bandas (IVDN): utilizada para realçar as diferenças espectrais de um par de bandas, para aumentar o contraste entre solo e vegetação. Para a banda do infravermelho próximo, utilizou-se a banda 4, e para a banda do vermelho, utilizou-se a banda 3. 
4. Composição multiespectral ajustada (b3 + IVDN + b1): esse procedimento foi realizado utilizando-se a luz vermelha na banda 3, a luz verde na imagem IVDN e a luz azul na banda 1, o que possibilitou analisar e diferenciar as áreas de degradação e da biomassa.

5. Segmentação: nesse processo, dividiu-se a imagem em regiões que correspondem às áreas de interesse da aplicação. Os parâmetros utilizados para similaridade e área do tamanho do pixel foram de 20 . O algoritmo "por regiões" foi escolhido por demonstrar áreas com aspecto mais contínuo, em que cada área possui características espectrais diferentes daquelas que a cercam.

6. Classificação: nessa etapa foi realizado o processo de extração de informação em imagens para reconhecimento de padrões e objetos homogêneos. O classificador utilizado foi o Bhattacharya, com limiar de aceitação de 99\%, algoritmo disponível no Spring para classificar regiões de uma imagem segmentada. Esse algoritmo usa as amostras de treinamento para estimar a função densidade de probabilidade para as classes apontadas no treinamento.

A partir da análise e interpretação visual das imagens TM e observações preliminares de campo, foram identificadas classes de interesse (vegetação densa, vegetação semidensa, agropecuária (cultivos/pecuária), corpos d’água e mata ciliar), para a geração do mapa de uso e ocupação da terra.

Essas classes de vegetação foram definidas em campo, pois, em determinadas situações, notou-se que em alguns fragmentos ainda não havia processo de antropização, logo, essas áreas foram caracterizadas como vegetação densa. Por outro lado, onde foi observado que houve alguma perturbação dessa vegetação, classificou-se como vegetação semidensa, e como mata ciliar aquela vegetação que se observou ao longo de cursos de rios, riachos etc.

Por meio da classificação digital das imagens, foram confeccionados os mapas por meio do módulo Scarta 5.1.3 do Spring.

\section{RESULTADOS E DISCUSSÃO}

\section{Dinâmica do uso e cobertura da terra}

No ano de 1987, a vegetação, tanto a densa como a semidensa, tinha 42,21\% da área de Floresta, ou seja, o município possuía quase metade da área de vegetação (Tabela 1). Em relação à classe de solo exposto, a área possuía 108.570 ha (ou 29,32\%) do território da região de estudo. A classe agropecuária encontrava-se em maior concentração no entorno dos corpos d'água e possuía uma área de 81.223 ha (ou $21,94 \%$ ) do município. Essa concentração deveu-se à maior disponibilidade de água, que é de suma importância para as áreas tanto agrícolas como de pastagem.

Tabela 1. Classes de uso e cobertura da terra no ano de 1987, 1997 e 2008, Floresta (PE).

Table 1. Classes use and land cover in 1987, 1997 and 2008, Floresta (PE).

\begin{tabular}{lcccccc}
\hline \multirow{2}{*}{ Classe de Uso } & \multicolumn{2}{c}{ Outubro de $\mathbf{1 9 8 7}$} & \multicolumn{2}{c}{ Setembro de 1997 } & \multicolumn{2}{c}{ Novembro de 2008 } \\
\cline { 2 - 7 } & Área (ha) & $\mathbf{\%}$ & Área (ha) & \% & Área (ha) & \% \\
\hline Vegetação densa & 8.324 & 2,25 & 14.658 & 3,96 & 10.434 & 2,82 \\
Vegetação semidensa & 147.940 & 39,96 & 128.462 & 34,70 & 90.942 & 24,56 \\
Solo exposto & 108.570 & 29,32 & 134.564 & 36,34 & 140.431 & 37,93 \\
Agropecuária & 81.223 & 21,94 & 64.382 & 17,39 & 102.537 & 27,69 \\
Corpos d'água & 3.871 & 1,04 & 17.673 & 4,77 & 18.805 & 5,08 \\
Mata ciliar & 20.340 & 5,49 & 10.509 & 2,84 & 7.098 & 1,92 \\
\hline Total & 370.248 & 100.00 & 370.248 & 100 & 370.248 & 100 \\
\hline
\end{tabular}

Os corpos d'água totalizaram 3.871 ha, apresentando apenas 1,04\% de todo o município. Esse baixo percentual se deve à época, pois ainda não existia uma política forte de combate à seca, como criação de barragens, poços e açudes. Apesar do pouco volume d'água nesse período, a classe mata ciliar apresentou 20.320 há, com 5,49\% do território de Floresta. Como a drenagem é intermitente em sua maioria e nesse ano foi constatado que já não havia precipitação há dois meses, isso explica o porquê da classe mata ciliar ter sido superior aos corpos d'água. Dessa maneira, a partir da figura 3, pode ser visualizado o mapa da cobertura e uso da terra no ano de 1987. 


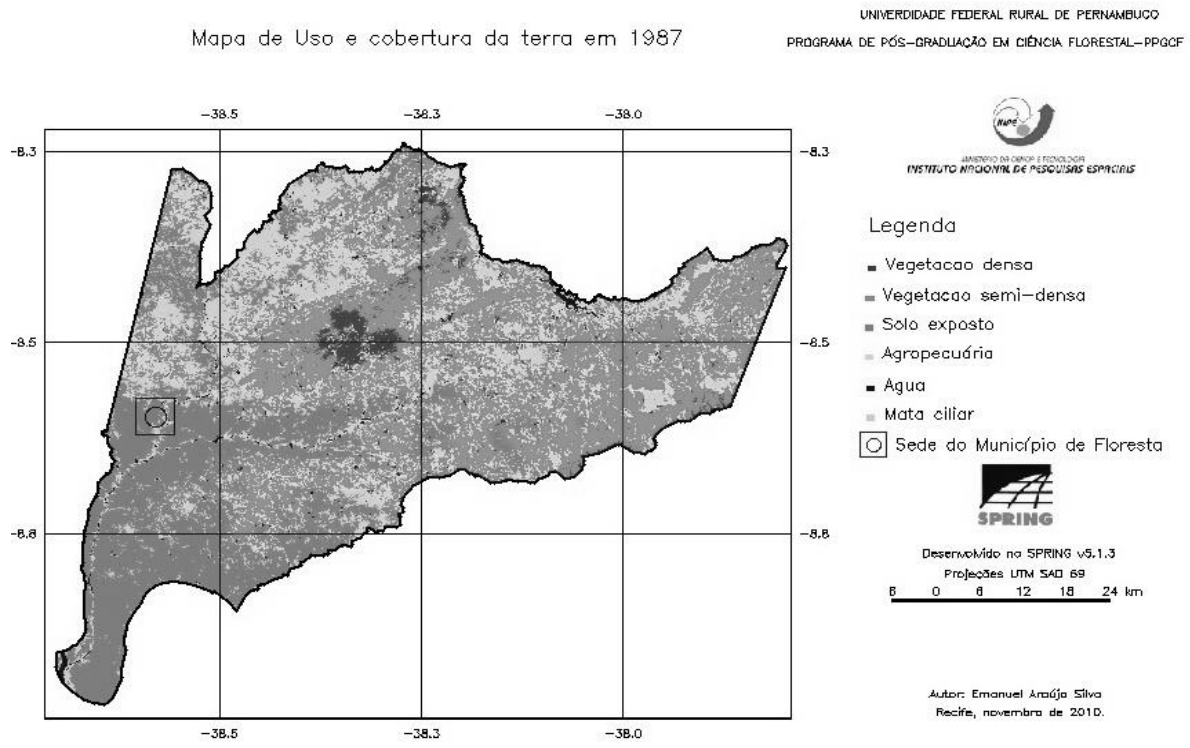

Figura 3. Mapa de uso e cobertura da terra em 1987 no município de Floresta (PE).

Figure 3. Map of use and land cover in 1987 in the Municipality of Floresta (PE).

No ano de 1997 houve um aumento na classe de vegetação densa de $1,71 \%$, o que equivale a 6.334 ha (Tabela 1). Em compensação, quando analisadas a vegetação densa e semidensa como uma única classe, houve uma diminuição na vegetação em 3,55\%, o equivalente a 13.144 ha de perda florestal.

Houve também uma mudança na posição da vegetação densa em relação ao ano de 1987, uma vez que, na obtenção da imagem de 1997, o solo encontrava-se úmido naquela região, pois nesse ano as precipitações ocorreram de uma forma bem mais distribuída ao longo do ano, o que pode ter causado uma migração e consequentemente um aumento da vegetação densa em relação ao período anterior (IBGE, 2010).

Em relação ao solo exposto, houve um aumento de 7,02\%, o equivalente a 25.994 ha. A classe agropecuária teve um decréscimo de 16.841 ha, o que correspondeu a $4,55 \%$ a menos em relação à mesma classe do ano de 1987. De acordo com Kleinpaul (2005), essa diminuição pode ser explicada pelo fato de agropecuária e solos expostos estarem intimamente ligados, pois fazem parte de áreas agrícolas. Solos expostos geralmente estão em pousio ou em fase de preparo para cultivos agrícolas. Por isso teria havido bastante variação entre essas duas classes, dependendo da época do ano e também das condições climáticas.

Outro fator também bastante plausível para a diminuição da classe agropecuária foi a diminuição da população de Floresta, com os desmembramentos dos seus distritos, elevados à categoria de municípios, e pelo êxodo rural nessa época, totalizando aproximadamente 10.000 habitantes a menos em relação ao período anterior (IBGE, 2010).

Os corpos d'água tiveram um aumento considerável de 13.802 ha, o que equivale a um acréscimo de 3,73\% em relação ao período anterior, Isso pode ser explicado pela criação, em 1988, da Usina Hidrelétrica Luiz Gonzaga (Itaparica), em Petrolândia (PE), a qual produziu uma maior vazão d'água para Floresta com o alargamento do rio São Francisco, cujo reservatório inundou uma área de $834 \mathrm{~km}^{2}$, e também por esse período ter tido uma maior presença governamental, no sentido de aliviar a seca na construção de poços e açudes.

A redução da área de mata ciliar de 9.811 ha, o equivalente a 2,65\%, pode estar associada com o aumento da vazão de água, pois a população se concentra nos locais onde há uma maior disponibilidade hídrica e consequentemente retira a mata ciliar para preparar o solo para a agricultura.

A partir da figura 4, pode ser visualizado o mapa da cobertura e uso da terra no período de 1997.

Ainda na tabela 1, para 2008, observa-se que todas as classes de vegetação diminuíram: a vegetação densa perdeu 4.224 ha e a vegetação semidensa foi suprimida em 37.520 ha, o que totalizou uma perda de 11,24\% de vegetação em comparação com o período de 1997, passando de 38,66\% para $27,38 \%$. 


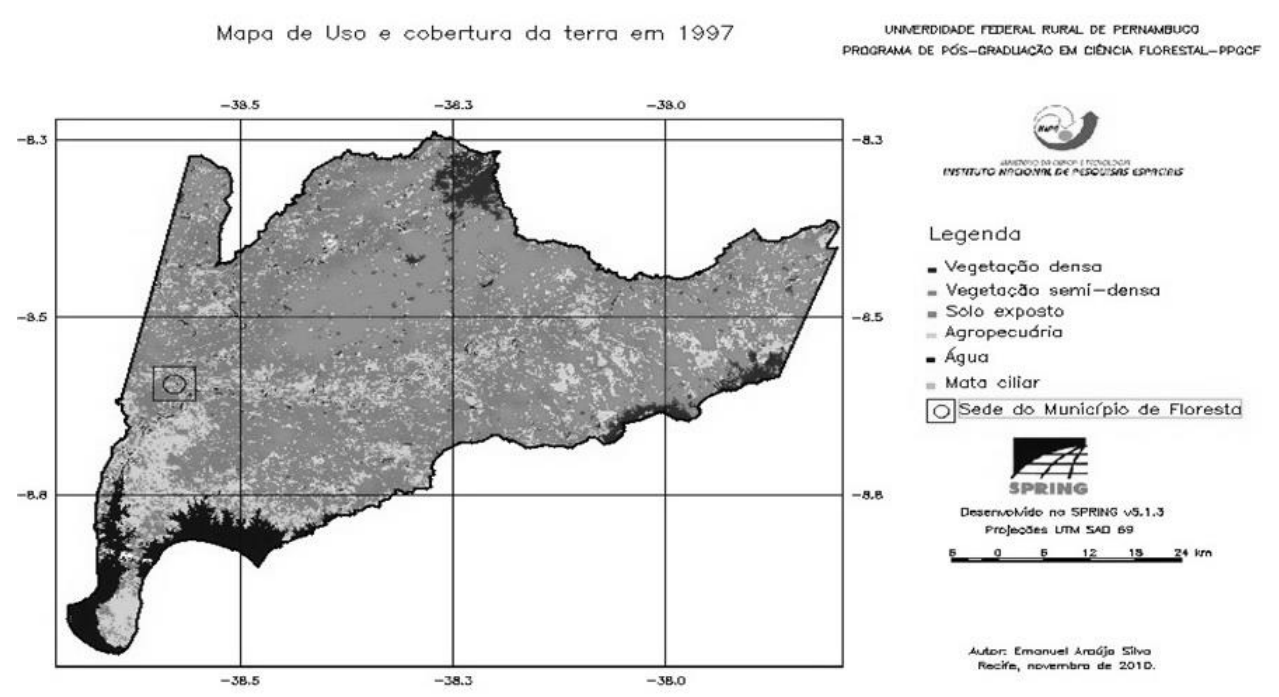

Figura 4. Mapa de uso e cobertura da terra em 1997 no município de Floresta (PE).

Figure 4. Map of use and land cover in 1997 in the Municipality of Floresta (PE).

Outro fator que evidenciou a supressão de vegetação foi a necessidade das obras da transposição do rio São Francisco do eixo leste, que vai de Floresta (PE) a Monteiro (PB), num percurso de $220 \mathrm{~km}$ em que se desmatou 430 ha para dar lugar aos canais, reservatórios, canteiros de obra, estradas de serviço e locais de extração de terra e pedra, como nota-se na figura 5.

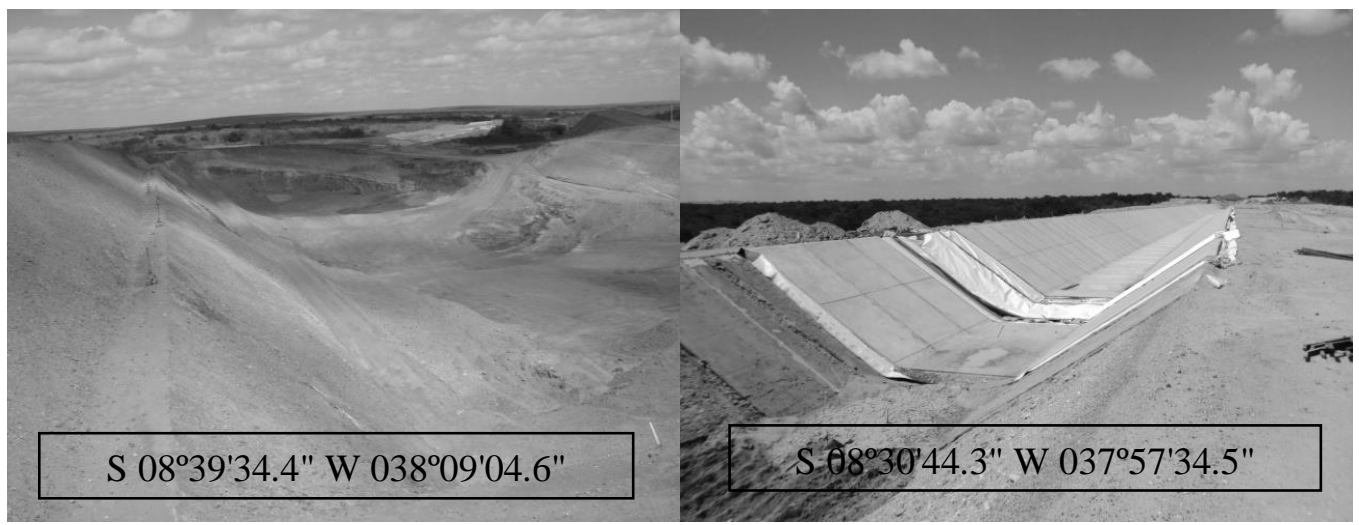

Figura 5. Obras de transposição do rio São Francisco.

Figure 5. Works of transportation of rio São Francisco.

A classe solo exposto teve um aumento de 5.868 ha, o equivalente a um incremento de $1,59 \%$ em relação a todo o território do município, devido principalmente às obras de transposição do rio São Francisco e à falta de chuvas, que já durava três meses, contribuindo dessa forma ao aumento de áreas degradadas, causando uma maior pressão nas áreas que já apresentavam certo grau de degradação.

A classe agropecuária obteve um ganho de 38.155 ha, ou seja, um aumento de 10,3\% em relação a 1997. Esse aumento pode estar associado ao fato de que, de acordo com a Agência Estadual de Planejamento e Pesquisas de Pernambuco (CONDEPE), o município possui 154.000 cabeças de caprinos, sendo líder da produção em Pernambuco, e terceiro produtor estadual de ovinos e de melão, atividades estas favorecidas por uma maior disponibilidade de água, apesar da seca, tornando necessário expandir as fronteiras agrícolas para abastecer uma maior demanda da população e mercados regionais.

Em 2008 houve um acréscimo de 1.132 ha de corpos d'água, equivalente a um aumento de $0,32 \%$, devido principalmente à construção de açudes. A classe mata ciliar teve um decréscimo de 3.411 ha, com uma diminuição percentual de $0,92 \%$. A retirada desse tipo de vegetação para a entrada de 
cultivos agrícolas pode acarretar aumento significativo dos processos de erosão do solo, com prejuízos à hidrologia regional, evidente redução da biodiversidade e degradação de imensas áreas, que altera o volume natural das nascentes. Esse processo de eliminação da vegetação ciliar pode resultar num conjunto de problemas ambientais, como a extinção de espécies da fauna e flora, mudanças climáticas locais e assoreamento do leito dos rios e seus afluentes.

Uma real extensão dos problemas encontrados no período de 2008 fica evidente a partir da figura 6, com o mapa da cobertura e uso da terra no período de 2008.

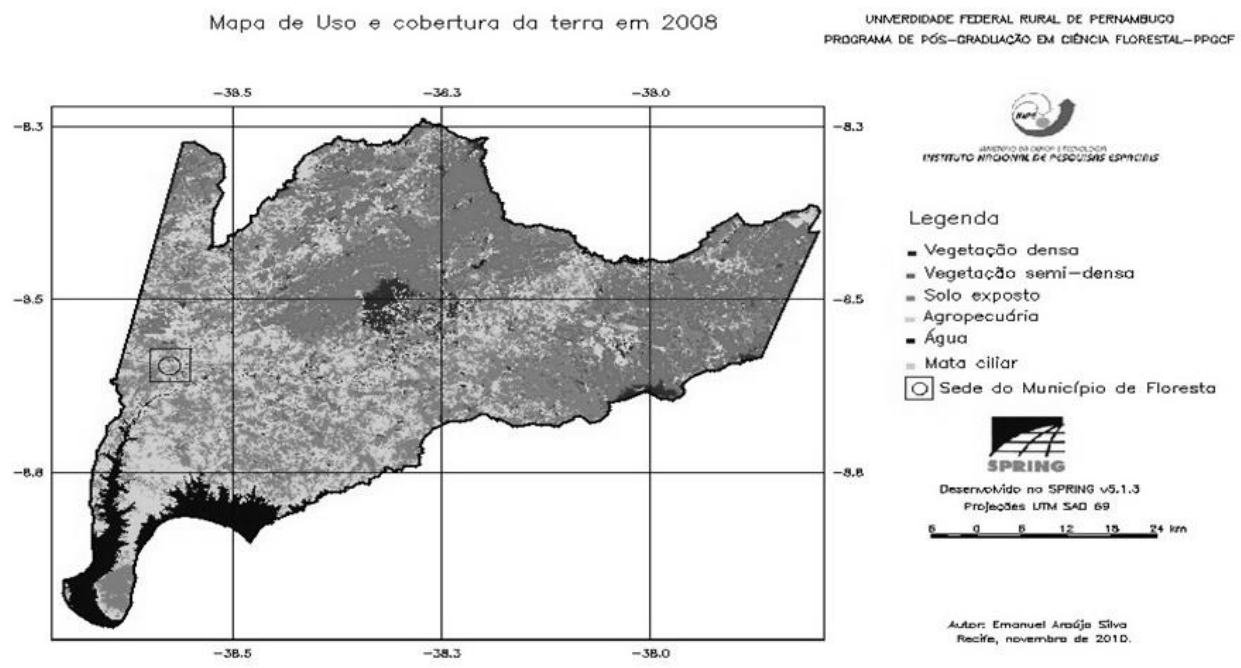

Figura 6. Mapa de uso e cobertura da terra em 2008 no município de Floresta (PE). Figure 6. Map of use and land cover in 2008 in the Municipality of Floresta (PE).

Parte da retirada da cobertura vegetal se deve ao sistema adotado desde a colonização, o qual se baseou na exploração dos recursos naturais, em particular da vegetação natural, que era desmatada para um sistema de exploração agrícola e pecuária muito intensa (SOUZA, 2007).

\section{CONCLUSÃO}

- A diminuição da cobertura florestal do município entre 1987 e 2008 foi a principal consequência da interação entre clima, pressão antrópica por recursos florestais, necessidade de expansão urbana e atividades agropecuárias.

- O município apresentou alto risco de áreas com solo exposto, pela pressão que o antropismo vem exercendo ao longo do tempo, comprometendo a qualidade de vida e consequentemente gerando problemas ambientais, sociais e econômicos.

- Por meio dos dados obtidos em campo e dos mapas temáticos produzidos, foi possível monitorar de forma satisfatória as transformações pela quais o município de Floresta vem passando quanto ao uso da terra.

- Com o banco de dados criado, será possível confeccionar modelos capazes de simular a cobertura florestal no município de Floresta (PE) e subsidiar os poderes públicos municipal, estadual e federal quanto à definição de políticas de gestão florestal sustentável.

- Salienta-se a importância da gestão florestal no semiárido para se combater a perda de vegetação, formando conhecimento científico acerca da dinâmica florestal, gerando políticas públicas para gerir e explorar sustentavelmente a cobertura florestal do município de Floresta e da região de carvoejamento, fiscalizando ações que levam ao antropismo. Sendo assim, criam-se bases sólidas de conhecimento para formação de banco de dados e de modelos capazes de simular a cobertura florestal no município, o que permite administrar o uso do solo de forma que mantenha as suas capacidades de uso tanto no presente como no futuro, agregando valores aos produtos florestais. 


\section{AGRADECIMENTOS}

Aos índios Pipipã, pela ajuda em campo, necessária à realização do trabalho, e à Fundação de Amparo à Ciência e Tecnologia do Estado de Pernambuco (FACEPE), pela bolsa disponibilizada para o estudo.

\section{REFERÊNCIAS}

AGÊNCIA ESTADUAL DE PLANEJAMENTO E PESQUISAS DE PERNAMBUCO (CONDEPE). Cadeias e Arranjos Produtivos. Região de Desenvolvimento Sertão de Itaparica. Disponível em: <HTTP://200.238.107.167/c/portal/layout?p_|_id=PUB.1557. 139>. Acesso em: 20/11/2010.

ANDRADE-LIMA, D. 1960. Estudos fitogeográficos de Pernambuco, Recife. Arquivos do Instituto de Pesquisas Agropecuárias 5: 305 - 334.

ANDRADE, G. O.; LINS, R. C. 1964. Introdução ao estudo dos "brejos" pernambucanos. Recife. Arquivos do ICT. Instituto de Ciências da Terra, Universidade do Recife. v. 2., p. 21 - 34.

LINS, R. C. Áreas de exceção do agreste de Pernambuco. Recife, SUDENE, 1989. 327 p.

BALDINI, K. B. L. Etnoconhecimento como ferramenta para conservação de recursos naturais no Parque Nacional do Itatiaia. 2008. 178 p. Dissertação (Mestrado em Ciência Ambiental) - Universidade Federal Fluminense, Niterói.

BANCO DO NORDESTE DO BRASIL (BNB). Proposta de dimensionamento do semiárido brasileiro. Fortaleza: BNB, 2005. 108 p.

COMPANHIA DE PESQUISA DE RECURSOS MINERAIS (CPRM). Serviço Geológico do Brasil. Projeto cadastro de fontes de abastecimento por água subterrânea. Diagnóstico do município de Floresta, Estado de Pernambuco, 2005. 33 p.

EMPRESA BRASILEIRA DE PESQUISA AGROPECUÁRIA (EMBRAPA). Diagnóstico Ambiental do Município de Floresta, Pernambuco. Rio de Janeiro-RJ: EMBRAPA, 2001. (Circular Técnica, ISSN 1517-5146). Disponível em: <http://www.cnps.embrapa.br/solosbr/pdfs/circulartecnica10diagamb floresta.pdf $>$. Acesso em: 11/05/2010.

INSTITUTO BRASILEIRO DE GEOGRAFIA E ESTATÍSTICA (IBGE). Manual técnico de uso da terra. (Manuais técnicos em Geociências, n. 7). Rio de Janeiro: IBGE, 2006. 91 p.

Instituto Brasileiro de Geografia e Estatística. Cidades do Brasil. 2010. Disponível em: <http://www.ibge.gov.br/cidadesat/topwindow.htm?1>. Acesso em: 15/10/2010.

JACOMINE, P. K. T.; CAVALCANTI, A. C.; BURGOS, N.; PESSOA, S. C. P. Levantamento exploratório - reconhecimento de solos do Estado de Pernambuco. Recife, MA/DNPEA SUDENE/DRN, 1973. v. 1. (Boletim técnico, 26).

KLEINPAUL, J. J. Análise multitemporal da cobertura florestal da microbacia do Arroio Grande, Santa Maria, RS. 80 p. Dissertação (Mestrado em Engenharia Florestal) - Universidade Federal de Santa Maria. Santa Maria, 2005.

LEAL, I. R.; TABARELLI, M.; SILVA, J. M. C. Ecologia e conservação da Caatinga. 2. ed. Recife: Editora Universitária da UFPE, 2005. 822 p.

MARIANO NETO, B. Ecologia e imaginário: memória cultural, natureza e submundialização. João Pessoa: CT/Editora Universitária/UFPB, 2001. 206 p.

METZGER, J. P. Estrutura da paisagem e fragmentação: análise bibliográfica. Anais da Academia Brasileira de Ciências, v. 71, n. 3, p. 445 - 463, 1999.

RIBEIRO, C. A. S.; SILVA, J. A. A.; FERREIRA, R. L. C.; MEUNIER, I. M. J.; FERRAZ. I. Seleção de modelos volumétricos para leucena no agreste de Pernambuco. Brasil Florestal, v. 20, n. 72, p. 37 - 45, 2001. 
SALES, M. F.; MAYO, S. J.; RODAL, M. J. N. 1998. Florestas serranas de Pernambuco: um checklist das plantas vasculares dos brejos de altitude. Imprensa Universitária. Universidade Federal de Pernambuco. Recife. 130 p.

SOUZA, C. M. B. M. Desertificação. Disponível em: <HTTP://www.cenedcursos.com.br/index2.php? option=com_content\&do_pdf=1\&id=48>. Acesso em: 05/11/2010.

TILMAN, D.; FARGIONE, J.; BRIAN, W.; D'ANTONIO, C.; DOBSON, A.; HOWARTH, R.; SCHINDLER, D.; SCHLESINGER, W. H.; SIMBERLOFF, D.; SWACKHAMER, D. Forecasting agriculturally driven global environmental change. Science, v. 292, p. 281 - 284, 2001. 